Academic Platform Journal of Engineering and Science

journal homepage: http://apjes.com/

\title{
An Elevator Control Algorithm Optimizing Privileged Use
}

\author{
*1 Mümine YILDIZ, ${ }^{2}$ Mehmet KARALI \\ ${ }^{1}$ Necmettin Erbakan University Dept. of Mechatronics Engineering, Konya, Turkey, mumineyildiz@konya.edu.tr, \\ 2 Necmettin Erbakan University Dept. of Mechatronics Engineering, Konya, Turkey, m.karali@konya.edu.tr, iD \\ Research Paper \\ Received Date: 08.04.2018 \\ Accepted Date: 12.07.2018
}

\begin{abstract}
Elevators are expected to fulfill the many different needs of passengers, which also differ depending on the type of building they are in. The absence of flexible software algorithms cause some elevators to be allocated to private usage in busy places like hospitals, hotels, and malls. Often this allocation, taking into consideration the ratio of private to public passengers, is unbalanced; in which case, heavily-used elevators, on top of risking break-downs and becoming out of service, operate unsatisfactorily. In this study, a control algorithm has been developed to authorize both private and public users, instead of distributing elevators between private and public passengers. In this way, service times for all users were optimized. The algorithm was tested with 100 scenarios on a prototype, while a total of 55000 scenarios have been simulated with Excel program. Differences in duration of both waiting and travel times have been compared yielding results which show significant advantages.
\end{abstract}

Keywords: Privileged Usage, Optimization, Elevator Control.

\section{INTRODUCTION}

With the rise in building height, well-being, and among other factors, population, an increased expectation in the flexibility of elevator performance and also in its ability to address needs of users in all kinds of buildings has surfaced. Thus, in order to add elaborate properties and qualities to elevator systems, currently there is a manifold of research and development being done with differing approaches. Achieving the best possible elevator performance which can answer more specific needs is now a common goal. To exemplify, the following advancements may be given: the differing performances within a day and also during holidays which take into account the fluctuations in the flow of elevator traffic on those days and hours, the directing of elevator car accordingly with passenger floor densities by discerning the number of passengers waiting on each floor, the speedy exit of passengers in emergency situations by taking passenger floor densities into account [1-4].

One other necessity encountered, related with usage priority, is the prevention of loss of time that may be experienced by passengers such as government authorities, namely: ministers, governors, judges, rectors, deans in public buildings; chief physicians, ER doctors and nurses in hospitals; and administrators and staff in social and community centers. Practices of designating separate elevators for the use of Very Important People (VIP) and also the canceling, by authorized passengers, of incoming floor requests through a card or key medium from inside of the elevator car, may be counted among current methods applied in order to more efficiently service said passengers and minimize such loss of time. These methods result in low usage densities of VIP designated elevators while eventually higher traffic densities of other elevators become inevitable and risk being insufficient in meeting demand. Meanwhile, because of unauthorized use of speciallydesignated elevators, problematic situations may occur, especially in the case of medical emergencies. As for systems which incorporate a key or card system, they reduce efficiency and are cumbersome due to the amount of time it takes for the elevator car to reach authorized passenger.

In a study resembling this one in aspect of categorizing users, passengers were classified as Normal, VIP and Strangers, and different weight factors were assigned to the objective function for each class to minimize the elevator waiting time and energy use. For the recognition of the users by the system, the face was scanned and compared with previously recorded photographs. However, this method increases the waiting time for normal users [5].

In this study, one normal mode and three privileged elevator modes are defined to classify passengers, and the system is operated by different preset algorithms acting according to the authorization rank of pre-designated privileged users. Elevator movement regarding privileged and normal passengers was defined from scratch thanks to 
decision tables. Karnough Maps were benefited from when implementing the defining tables to the PLC. Elevator behavior is dictated for every situation according to decision tables by means of Karnough Maps and subprograms. When the need for authorized/VIP use arises, privileged use is provided by means of entering a proprietary password where after the elevator is directed to the concerned passenger. The elevator is then rendered unavailable for other users, being either totally or partially blocked depending on the rank of authority of privileged passenger, and works exclusively for that passenger until target is reached or until a higher ranking user sends a request. Thus all elevators in the building are able to provide privileged use whenever necessary. Moreover, elevators designated to privileged use are prevented from being idle when not occupied by a VIP, and the traffic density of elevators in normal use is optimized since elevator traffic is distributed collectively.

\section{ELEVATOR OPERATION MODES AND THEIR IMPLEMENTATION}

\subsection{Elevator Operation Modes}

Normal mode: Normal mode has been defined as the elevator algorithm that operates without the need for entering password and does not provide privileged use. The logic used in the elevator control algorithm for normal mode operation is Selective Collective Automatic
Operation which responds to all requests and is commonly used in many elevator systems, rather than a first come first serve method [6].

The starting status of elevator control system is Normal operation mode, until there is a privileged call. An elevator that is operating in Normal Mode when privileged user password is received, changes from Normal mode to the corresponding privileged mode, according to the rank of the call. Different behaviors are defined for transitions between elevator operation modes. While an elevator is operating in normal mode, if a Rank1 call is received and there isn't any higher ranked call, it changes to Rank1 mode and previous floor calls get canceled. If there is a Rank2 call but no Rank3, the mode will change to Rank2 and previous floor calls will be canceled. However, car calls in the opposite direction of the destination are affectively abandoned after reaching the floor from which the Rank2 call was made. That is, the only previously-made car calls that are fulfilled are those that lie on the path of the elevator which is going to the floor of the Rank 2 call. In Rank2 mode, calls besides those of Rank2 and Rank3 are not accepted. Upon a Rank3 call, all previous calls are canceled, regardless, and no calls except for other Rank3 calls are accepted. After the privileged calls are fulfilled, the elevator operation mode automatically shifts back to Normal Mode. Transitions between normal mode and other modes are shown in Table 1.

Table 1. Reaction of elevator operation modes according to incoming call rank.

\begin{tabular}{|c|c|c|c|c|}
\hline & Normal Mode & Rank1 Mode & Rank2 Mode & Rank3 Mode \\
\hline $\begin{array}{l}\text { Normal } \\
\text { Call }\end{array}$ & $\begin{array}{c}\text { Apply Selective } \\
\text { collective automatic } \\
\text { operation. }\end{array}$ & Do not accept. & Do not accept. & Do not accept. \\
\hline $\begin{array}{l}\text { Rank1 } \\
\text { Call }\end{array}$ & $\begin{array}{l}\text { If there isn't Rank2 and } \\
\text { Rank3, switch mode to } \\
\text { Rank1. Cancel revious } \\
\text { floor calls. Fulfill } \\
\text { previous car calls. }\end{array}$ & $\begin{array}{c}\text { Apply Selective } \\
\text { Collective Automatic } \\
\text { Operation. }\end{array}$ & Do not accept. & Do not accept. \\
\hline $\begin{array}{l}\text { Rank2 } \\
\text { Call }\end{array}$ & $\begin{array}{l}\text { If there isn't Rank3, } \\
\text { switch mode to Rank2. } \\
\text { Cancel car calls in the } \\
\text { opposite direction of the } \\
\text { destination and previous } \\
\text { floor calls. Fulfill } \\
\text { previous car calls an } \\
\text { route. }\end{array}$ & $\begin{array}{l}\text { If there isn't Rank3, } \\
\text { switch mode to Rank2. } \\
\text { Cancel car calls in the } \\
\text { opposite direction of the } \\
\text { Destination and previous } \\
\text { floor calls. Fulfill } \\
\text { previous car calls an } \\
\text { route. }\end{array}$ & $\begin{array}{c}\text { Apply Selective } \\
\text { Collective Automatic } \\
\text { Operation. }\end{array}$ & Do not accept. \\
\hline $\begin{array}{l}\text { Rank3 } \\
\text { Call }\end{array}$ & $\begin{array}{l}\text { Cancel all previous calls. } \\
\text { Halt at the closest floor. } \\
\text { Make announcement to } \\
\text { evacuate. }\end{array}$ & $\begin{array}{l}\text { Cancel all previous calls. } \\
\text { Halt at the closest floor. } \\
\text { Make announcement to } \\
\text { evacuate. }\end{array}$ & $\begin{array}{l}\text { Cancel all previous } \\
\text { calls. Halt at the } \\
\text { closest floor. Make } \\
\text { announcement to } \\
\text { evacuate. }\end{array}$ & $\begin{array}{c}\text { Apply Selective } \\
\text { Collective } \\
\text { Automatic Operation }\end{array}$ \\
\hline
\end{tabular}

Rank1 mode: Rank1 mode is the lowest privileged rank and was created for users with low priority. Therefore, answering times are longer than Rank2 mode but shorter than normal mode. While in Rank1 mode, incoming Normal rank calls are not accepted. When recieved, incoming Rank2 calls are answered, though only previous 
Rank1 calls that are not in the reverse direction are fulfilled. If the incoming call is Rank3, previous calls are canceled and the passengers are taken to the nearest floor. While in Rank1 mode, if there is new incoming Rank1 call, Selective Collective Automatic Operation is applied.

Rank2 mode: Rank2 mode is a medium rank privileged mode. The call response duration is longer than Rank3 mode but shorter than Rank1 mode. In Rank2 mode, Normal and Rank1 calls are not accepted. If the incoming call is Rank2, Selective Collective Automatic Operation is applied between calls. When a Rank3 call is registered, the operating mode changes to Rank3 mode and halts at the closest floor; then an announcement is made for Rank2 users to evacuate cabin before going to Rank3 user.

Rank3 mode: Rank3 mode is the highest privileged mode. Rank3 call is answered by the system in the fastest way possible. This level has been created to provide privileged usage to the most authorized or most urgent of users. After the Rank3 call is received, all previous calls are canceled and the elevator car halts at the closest floor, making an announcement for previous passengers to evacuate before moving on to Rank3 user. In Rank3 mode, except for other Rank3 calls, no incoming call is accepted.

\subsection{Implementation of Improved Algorithms}

Control System: The generated algorithms have been tested on a King servo-controlled elevator prototype controlled by a Panasonic FPX-C38AT series PLC and WinTr SCADA interface. Conclusions from other studies using PLCs have discovered that PLCs are stable and reliable [7], resistant [8], energy saving [9] and also practical [10]. Taking these results into account, a PLC was preferred. In order to apply the complicated elevator algorithms correctly to the PLC, a logical solution was made using Karnaugh Maps, a parallel method previously proposed [11], rather than Mark Flow Diagrams [12] or State Diagrams [13]. Unlike reference [11], in this study, not only have state-combination circuits for input variables been created, but solutions were also produced using variables obtained with certain operations from within the PLC or as the result of variables obtained from another Karnough solution.

In order to reach the solution, the basic problem of the system is formed as subprograms related to each other and wherever needed Karnaugh maps have been used in the specified subprograms.

Input and output variables were determined for each solution; outputs were then obtained by establishing logic relations between inputs and outputs. By using the Karnaugh maps, the obtained output values were simplified and solved, and the obtained logic expressions were applied to PLC.

The Karnough solution of the mode determination subprogram is examined as an example. The mode determination subprogram determines the current operating mode and controls the transitions between operating modes according to the rank of incoming calls. The relationship between inputs and outputs during the mode determination process is shown in Table 2. For example, when the elevator is operating in Rank1 mode and there is a Rank2 call, but no Rank3 call, the mode changes to Rank2, disregarding any incoming Normal and Rank1 calls. The symbols assigned for input variables in the Karnaugh solution are given in Table 3 .

Table 2. Logic statements between inputs and outputs to determine the operating mode.

\begin{tabular}{|c|c|c|c|c|c|}
\hline \multicolumn{5}{|c|}{ Inputs } & \multirow[t]{2}{*}{ Outputs } \\
\hline Pre-call rank & Normal call & Rank1 call & Rank2 call & Rank3 call & \\
\hline \multirow{4}{*}{ Normal mode } & 1 & 0 & 0 & 0 & Normal mode \\
\hline & 1 & 1 & 0 & 0 & Rank1 mode \\
\hline & 1 & 1 & 1 & 0 & Rank 2 mode \\
\hline & 1 & 1 & 1 & 1 & Rank3 mode \\
\hline \multirow{4}{*}{ Rank1 mode } & 1 & $\overline{0}$ & $\overline{0}$ & $\overline{0}$ & \\
\hline & 1 & 1 & 0 & 0 & Rank1 mode \\
\hline & 1 & 1 & 1 & 0 & Rank2 mode \\
\hline & 1 & 1 & 1 & 1 & Rank3 mode \\
\hline \multirow{4}{*}{ Rank2 mode } & 1 & 0 & 0 & 0 & \\
\hline & 1 & 1 & 0 & 0 & Rank2 mode \\
\hline & 1 & 1 & 1 & 0 & \\
\hline & 1 & 1 & 1 & 1 & Rank3 mode \\
\hline \multirow{4}{*}{ Rank3 mode } & 1 & 0 & 0 & 0 & \\
\hline & 1 & 1 & 0 & 0 & Rank3 \\
\hline & 1 & 1 & 1 & 0 & Mode \\
\hline & 1 & 1 & 1 & 1 & \\
\hline
\end{tabular}


Table 3. Input variables for the Karnough solution.

\begin{tabular}{llll}
\hline \multicolumn{4}{c}{ Input Variables } \\
\hline Symbol & Pre-call rank & Symbol & Incoming call rank \\
\hline \hline A & Normal Mode & E & Normal call \\
\hline B & Rank1 Mode & F & Rank1 call \\
\hline C & Rank2 Mode & G & Rank2 call \\
\hline D & Rank3 Mode & H & Rank3 call \\
\hline
\end{tabular}

Table 4. Karnaugh solutions of Mode determination.

\begin{tabular}{|c|}
\hline Karnaugh Solutions \\
\hline $\begin{array}{l}\text { Karnaugh solution for determining Mode Normal mode } \\
\qquad \mathrm{AB}^{\prime} \mathrm{C}^{\prime} \mathrm{D}^{\prime} \mathrm{F}^{\prime} \mathrm{G}^{\prime} \mathrm{H}^{\prime}\end{array}$ \\
\hline $\begin{array}{l}\text { Karnaugh solution for determining Mode Rank1 mode } \\
\mathrm{A}^{\prime} \mathrm{BC}^{\prime} \mathrm{D}^{\prime} \mathrm{F} \mathrm{G}^{\prime} \mathrm{H}^{\prime}+\mathrm{AB}^{\prime} \mathrm{C}^{\prime} \mathrm{D}^{\prime} \mathrm{F} \mathrm{G}^{\prime} \mathrm{H}^{\prime}\end{array}$ \\
\hline $\begin{array}{l}\text { Karnaugh solution for determining Mode Rank2 mode } \\
\mathrm{A}^{\prime} \mathrm{B}^{\prime} \mathrm{CD}^{\prime} \mathrm{GH}^{\prime}+\mathrm{A}^{\prime} \mathrm{B} \mathrm{C}^{\prime} \mathrm{D}^{\prime} \mathrm{GH}^{\prime}+\mathrm{AB}^{\prime} \mathrm{C}^{\prime} \mathrm{D}^{\prime} \mathrm{GH}^{\prime}\end{array}$ \\
\hline $\begin{array}{l}\text { Karnaugh solution for determining Mode Rank2 mode } \\
\mathrm{A}^{\prime} \mathrm{B}^{\prime} \mathrm{C}^{\prime} \mathrm{D}^{\prime} \mathrm{H}+\mathrm{A}^{\prime} \mathrm{B}^{\prime} \mathrm{C} \mathrm{D}^{\prime} \mathrm{H}+\mathrm{A}^{\prime} \mathrm{B} \mathrm{C}^{\prime} \mathrm{D}^{\prime} \mathrm{H}+\mathrm{AB}^{\prime} \mathrm{C}^{\prime} \mathrm{D}^{\prime} \mathrm{H}\end{array}$ \\
\hline
\end{tabular}

Shown in Figure. 1 is the flow chart showing the inputs of both calls and car position, the main programs which work in the PLC, and output of car movement.

Elevator interface system: By using the SCADA program for elevator system design, the avoidance of time loss during the development of the system [14] was targeted in addition to the increase of automation owing to abilities presented by SCADA [15]. Three different pages were designed in the SCADA program. In the main page, the operation of the elevator is visualized instantaneously and the button and password panels created on the same page allow the elevator to be controlled.

On the Settings page, there are options for what kind of restrictions can be set when the maintenance period and maintenance time comes. For elevators without maintenance, options include slowing of speed, warning, or disabling. On the observation screen, statistical information about the distance traveled by the elevator and the usage rates of the floors is displayed while these statistical data are stored in the SQL database.

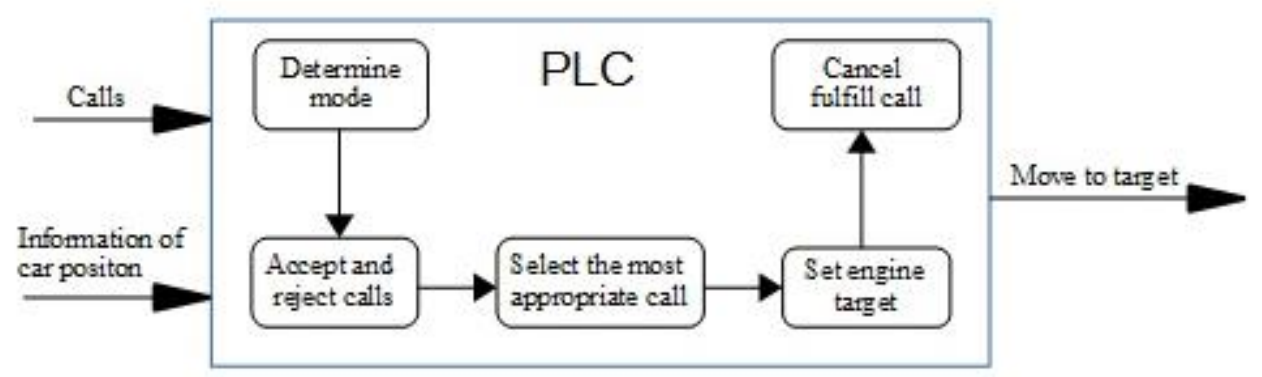

Figure. 1: Elevator operation flow chart.

On the main screen, password panels have been created for password operations of privileged users. The designed main screen is visible in Figure. 2. Through password panels; password recognition procedures, the information of privileged user rank, the floor that the privileged user is on, and floor that the privileged user wishes to go to are decoded. In the password entry process, the user special password can be mixed in with random numbers. The number entered after the "\#" sign is transferred to the system as target information. For example, a user with the password "9620" could key in a complex but random number sequence, up to 8 digits, such as the number "28396208 \# 4" so as to prevent the password from being learned by others. After entering the password, the rank of user is confirmed and the operation mode is determined accordingly.

Prototype: Motors generally used in elevator control include Synchronous motors, or reluctance motors, in which vibration problems can be avoided with control circuits [16]. The six storey elevator prototype, which has been produced for the purpose of experimental application, uses a brake servo motor set with the same technology as the synchronous motors. The position is controlled by the encoder on it; so there is no need to use a limit switch for the lift coats. However, limit sensors are used for safety purposes and to indicate the zero point of the motor.

Regarding the six storey elevator prototype design; for the PLC inputs, the push buttons were used as call buttons and numbered a total of 10 inputs for each floor button (updown), and 6 inputs for car calls; while 1 input was given to the servo motor home switch, adding up to a total of 17 inputs. Since the password panels can easily be integrated into the prototype later, and since it requires much more inputs than found in or can be added to the PLC, they have only been created on the SCADA program.

Push buttons with LEDs are used for specifying the activated call buttons. There are 16 buttons for this operation, so 16 outputs are required. For servomotor control, 1 servo open / close and 2 pulse outputs are needed. Therefore, a total of 19 outputs are needed; but since the PLC used has only 14 outputs, the number of outputs was increased by using the demultiplexer. 


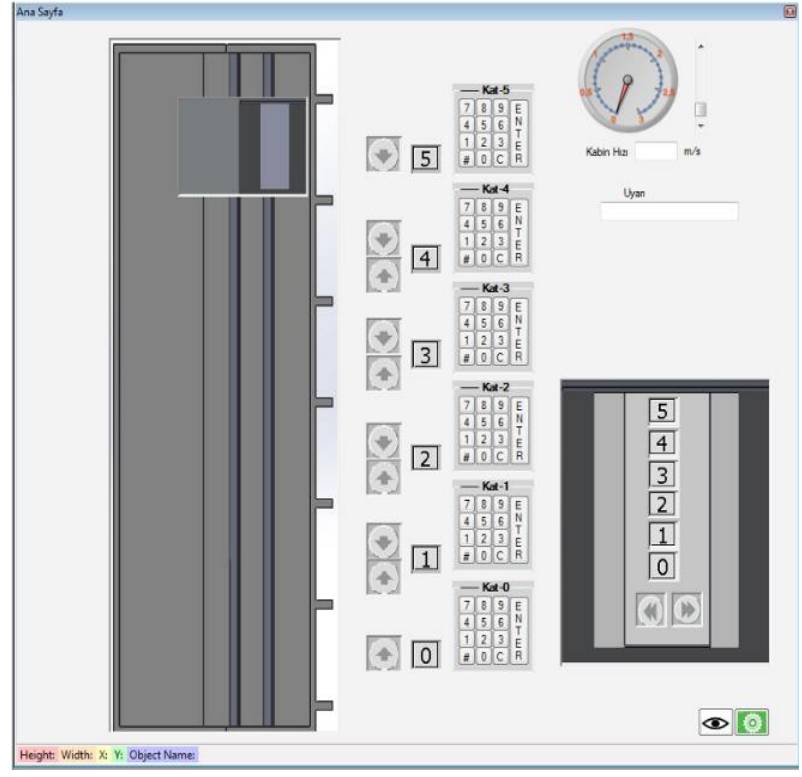

Figure 2: SCADA homepage screen.

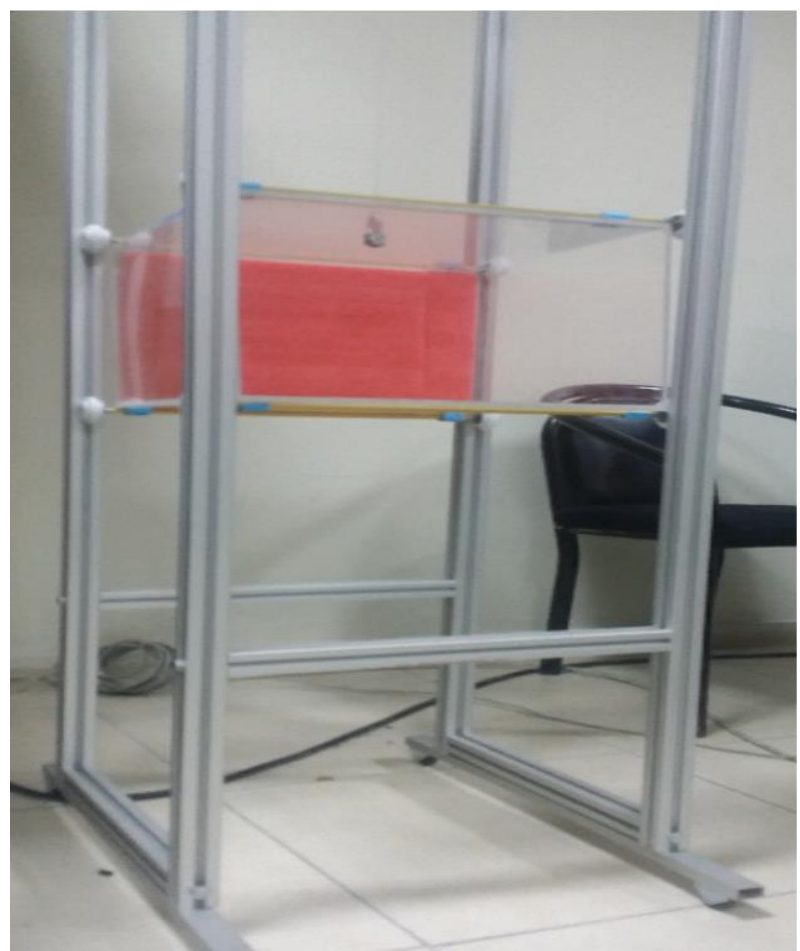

Figure 3: Prototype.

\section{ELEVATOR OPERATION MODES AND THEIR IMPLEMENTATION}

Around 100 scenarios have been created and run on the prototype and SCADA program to quantitatively determine the advantages of the enhanced privileged-usage modes. Then, random scenarios were created in Excel for alternative elevators with different floors and different traffic intensities in light of the data obtained. By running these many scenarios, data such as the time of arrival of the car, the time to reach the target, and the total elapsed time for each scenario have been obtained and compared.

Benchmarking was made in two aspects, the first being the proportional comparison, regarding advantages and disadvantages in elapsed time, between all four modes as well as between the normal and the three privileged modes. This was done by taking into consideration the duration it takes to reach the call floor, the duration it takes to reach the target floor, and the total elapsed time. After considering the traffic density of these hypothetical buildings, and assuming that the privileged-usage system be applied, the changes in traffic density and in-service durations of privileged modes were compared.

\subsection{Creating Scenarios and Calculation of Scenario Times}

In order for the randomly generated scenarios to be used by the system, they are first encoded in a logic framework and then analyzed by the system. Within scenarios, there are situations such as cancellation of previous calls and negation of calls made after a privileged one. For this reason the situations before and after the privileged call are taken into consideration when creating the scenarios. The scenario coding process has been done in a way that identifies whether the car buttons and floor buttons for each floor are active or inactive, and whether these calls are after or before the privileged call.Scenario encoding is elaborated in a sample scenario in Table 5.

In the scenario defined as "001000 011011110111000010 $110101111100 "$ ", each group represents a separate floor. To which floor the scenario groups belong to is specified through color coding in the table. Just beside the value which indicates the buttons activeness by "1" and passiveness by " 0 " is the value which indicates whether the call was or was not preceded by a privileged call, again valued as " 0 " if before the privileged call and as " 1 " if after the privileged call.

In order to analyze the operation of elevators with different traffic densities, some of the floor button values which are active in the created scenarios can be brought to the passive state so that the scenarios are in the desired traffic density range. After the creation of the scenarios, for quantitative analysis, equation (1) has been produced that is able to compute the time that passes for acceleration and deceleration during each halt. Observations were made in a selected public building and the data given below was used for making the mentioned equation. 
Table 5: Encoding of scenario.

\begin{tabular}{|c|c|c|c|c|c|c|}
\hline Floors & $\begin{array}{c}\text { Car } \\
\text { Buttons }\end{array}$ & $\begin{array}{c}\text { Privileged } \\
\text { calls pre/post } \\
\text { status }\end{array}$ & $\begin{array}{c}\text { Upwards } \\
\text { Direction } \\
\text { floor call }\end{array}$ & $\begin{array}{c}\text { Privileged } \\
\text { calls pre/post } \\
\text { status }\end{array}$ & $\begin{array}{c}\text { Downwards } \\
\text { Direction floor } \\
\text { call }\end{array}$ & $\begin{array}{c}\text { Privileged } \\
\text { calls pre/post } \\
\text { status }\end{array}$ \\
\hline Floor 5 & 0 & 0 & 1 & 0 & 0 & 0 \\
\hline Floor 4 & 0 & 1 & 1 & 0 & 1 & 1 \\
\hline Floor 3 & 1 & 1 & 0 & 1 & 1 & 0 \\
\hline Floor 2 & 0 & 0 & 0 & 0 & 0 & 1 \\
\hline Floor 1 & 1 & 1 & 0 & 1 & 0 & 0 \\
\hline Floor 0 & 1 & 1 & 1 & 1 & 110101 & 111100 \\
\hline \hline
\end{tabular}

$V=0.7 \mathrm{~m} / \mathrm{s}$ (Car average speed)

$h=3 m$ (Distance between floors)

$t_{i}=8.3 s$ (Acceleration - deceleration time $)$

$d_{a}:$ Number of storeys in two stops

$t:$ Total road to take time

$t= \begin{cases}\frac{2 h}{V} & d_{a}=1 \\ 2 t_{i}+\frac{2 h-V t_{i}}{V} & d_{a}=2 \\ \frac{\left(d_{a}-2\right) h}{V}+2 t_{i}+\frac{\left(2 h-V t_{i}\right)}{V} & d_{a}>2\end{cases}$

The equation (2) is obtained by adding the opening and closing times of the door, the passenger get-on and get-off times, and the traveling time.

$$
\begin{aligned}
& T: \text { Total elapsed time } \\
& d_{s}: \text { Number of pauses } \\
& t_{k}=4 s:(\text { Door opening }- \text { closing time }) \\
& t_{d}=10 \mathrm{~s}:(\text { Passenger ride time }) \\
& T=d_{s}\left(t_{k}+t_{d}\right)+t
\end{aligned}
$$

The time elapsed for each prepared scenario is calculated using these equations.

\subsection{Comparison of privileged usage modes}

Albeit there being differing numbers of floors for every building in cities, buildings that range from five to fifteen floors were chosen to be inspected in simulations. This was thought to be more appropriate and closer to average building height of urban and sub-urban areas. This has been done by simulating a five floored building, adding one floor, running the simulation, and repeating the process until a total of fifteen floors has been reached. For each of these buildings, 50 sample scenarios were run and from each scenario a list of average elapsed times was formed. All in all, 600 scenarios worth of data on average times was obtained and visualised in the form of graphs from a series of 11 buildings, ranging from five to 15 storeys.

Since the elevator density will vary depending on the number of floors, number of users, number of elevators and different time periods during the day, a density reference ranging from $5 \%$ to $100 \%$ was taken, instead of referring to a specific density coefficient. With each density value, scenarios were created again for aforementioned eleven buildings. Times spent in the elevator were likewise calculated.

The amount of time that passes after a call is made for the elevator to reach the call floor and the amount of time it takes for it to reach the target floor were calculated separately. To find the total time, both of these were added together.

However, since it is thought that the time it takes to reach the call and the time it takes to reach the target may differ according to the privileged rank of the call, the amount of time spent for every call was examined thrice additionally for the three privileged modes.

In the graph in Fig. 4, when the waiting times of the four operation modes are examined, Rank 3 mode is found to be the quickest, because all calls registered before get canceled. The longest waiting time belongs to the Normal mode. A difference was observed between the Rank1 and Rank 2 modes in that calls in the opposite direction of the car are canceled in the Rank2 mode, which lessens its waiting time. The reason that the Rank3 mode is unaffected by factors such as rises in elevator usage density is that when the Rank3 mode is activated by a Rank3 privileged user, all calls whatsoever, except for other Rank 3 calls, are canceled. In normal mode, Rank1 mode, and Rank 2 mode, the elapsed time significantly increases depending on the increase in elevator usage density. 


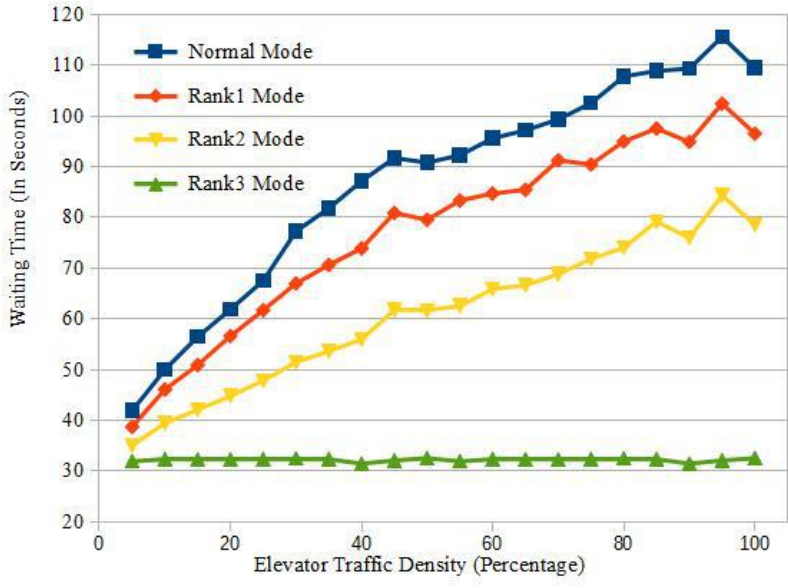

Figure 4: Graphic depicting waiting times of modes.

In Fig. 5, it can be seen that the Rank2 mode travel time, is closer to the travel time of Rank3 mode, due to the cancellation of the car calls in the opposite direction. Since an increase in elevator usage density also increases the likelihood of a car call between the call floor and the target floor, an increase, regardless of however little, in travel time was observed in the Rank 2 mode.

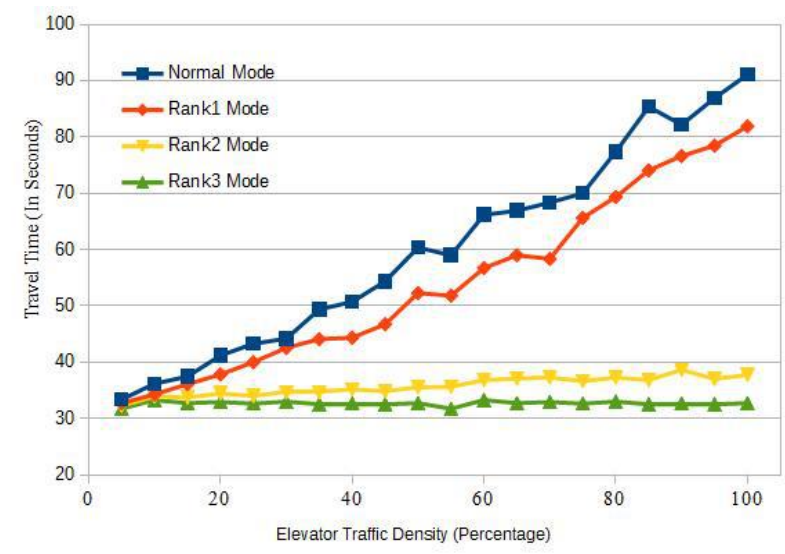

Figure 5: Graphic depicting travel times of modes.

In Fig. 6, when the total travel times are evaluated, it has been confirmed that similar results have been obtained to the ones foreseen when the algorithms were being formed.

To compare with current usages, first, the traffic density of elevators open to public use of the selected building was found to be $66 \%$ on average, while the VIPs' had $20 \%$ density. The traffic density is found to be at $43 \%$ on average when all elevators are used by all users if privileged use is exercised. As for privileged passengers, which are otherwise classified in current systems as VIP, the ratios given are 0.25 for Rank1 users, 0.60 for Rank2 users, and 0.15 for Rank3 users.

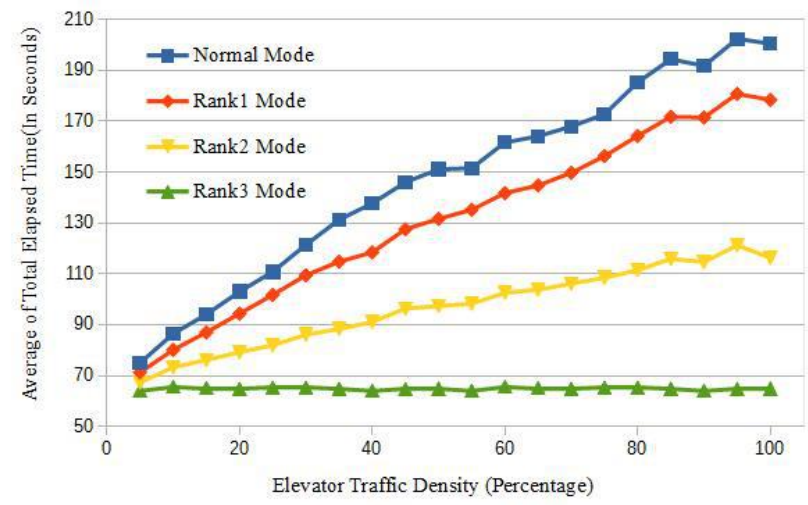

Figure 6: Graphic depicting travel times of modes.

The graph in Fig. 7 shows a detailed comparison of current public-usage density (60\%), current VIP-usage density $(20 \%)$, and the privileged elevator system usage densities for the four different modes $(43 \%)$ in relation to the average total elapsed times in seconds and the number of building floors.

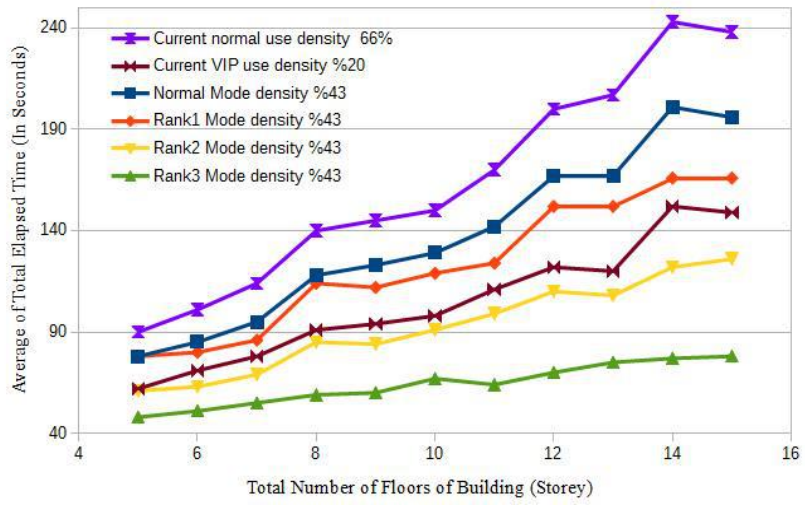

Figure 7: Graphic depicting travel times of modes.

The amount of time spent in the Normal mode, as expected, has dropped because there is a general distribution of elevator usage amongst all elevators owing to privileged use. Although the Rank1 mode has a higher usage density and is slower when compared with current VIP usage, it nevertheless answers Rank1 calls in a speedier fashion than Normal mode. Interestingly, although it is not the highest privileged mode, the Rank2 mode answers calls in a shorter time than current VIP usage. This stems from the fact that in current VIP usage, previous calls are all serviced. In addition, in the Rank 2 mode, floor calls and car calls in the opposite direction of the elevator are canceled, thus, the average total duration is lower than the average for current VIP use. The time spent in Rank3 mode is much shorter than in the current VIP mode; while all previous calls in Rank3 mode are canceled and no new calls are accepted, the current VIP usage not only allows for new calls, but also services previously made calls. 


\section{DISCUSSION AND CONCLUSION}

In today's society, the time loss of some elevator users is seen to be more important than others. A new strategy has been proposed under the name of Privileged Use so that these users can fulfill their need of elevator service as quickly as possible without being affected by heavy elevator traffic. The system provides four different modes of operation, according to predefined user rank, and activates one of the three privileged modes upon entry of predetermined proprietary password. The system also benefits normal users, for it eliminates the need for private elevators in buildings, thus opening up all existing elevators to public use. In order to measure the effectiveness of and the proportion of optimization achieved by the privileged use system, comparisons have been made with current elevator systems in buildings of differing heights. Results of simulation analysis have shown that both the overall density of elevator traffic and service time especially of higher privileged users has decreased. To exemplify, when compared with current VIP usage; the Rank2 and Rank3 modes answered calls in a less amount of time, while in Rank1 mode the calls took only a little longer to be answered than current VIP usage. Meanwhile normal users are able to receive elevator service considerably more swiftly due to increase of available elevators to them. Future works to be done include the development of privileged use algorithms for group elevators and multiple elevators.

\section{REFERENCES}

[1] A. Ürkmez, O. Haciislamoğlu, and M. Aydın, "Yolcu talebine göre asansör algoritmasının değiştirilmesi." Asansör Sempozyumu 2006 on TMMOB, 2006.

[2] H.-Y. Tang, B. Ding, W.-G. Qi, and Y.-M. Zhang, "Optimization of elevator group control scheduling with multi-strategy switch," in Machine Learning and Cybernetics, 2008 International Conference on, vol. 4. IEEE, 2008, pp. 2067-2072.

[3] J. Wang, Y. Shen, S. Wang, Q. Zhao, K. Nakamura, H. Yamada, and T. Tanaka, "Energy-saving algorithm for elevator group control system with cameras," in Intelligent Control and Automation (WCICA), 2014 11th World Congress on. IEEE, 2014, pp. 2654-2658.

[4] N. Ding, T. Chen, P. B. Luh, and H. Zhang, "Optimization of elevator evacuation considering potential over-crowding," in Intelligent Control and Automation (WCICA), 2014 11th World Congress on. IEEE, 2014, pp.
2664-2668.

[5] X. Liu and J. Ping, "A strategy of elevator group control based on passengers classifying," in Computational Intelligence and Software Engineering, 2009. CiSE 2009. International Conference on. IEEE, 2009, pp. 1-4.

[6] L. Cheded and M. Al-Mulla, "Control of a four-level elevator system using a programmable logic controller," International journal of electrical engineering education, vol. 39, no. 2, pp. 110-117, 2002.

[7] Y. Huang, W. Peng, and C. Liu, "Design of controlling system of higher layer elevator," Electronics and Signal Processing, pp. 185-189, 2011.

[8] S. Sehgal and V. Acharya, "Effect of plc and scada in boosting the working of elevator system," in Electrical, Electronics and Computer Science (SCEECS), 2014 IEEE Students' Conference on. IEEE, 2014, pp. 1-6.

[9] P. Wang, "A control system design for hand elevator based on plc," in Computational Intelligence and Design (ISCID), 2011 Fourth International Symposium on, vol. 1. IEEE, 2011, pp. 71-74.

[10] S. Htay and S. S. Y. Mon, "Implementation of plc based elevator control system," International Journal of Electronics and Computer Science Engineering, vol. 3, no. 2, pp. 91-100, 2014.

[11] C.-P. Chuang, X. Lan, and J. C. Chen, "A systematic procedure for designing state combination circuits in plcs," Journal of Industrial Technology, vol. 15, no. 3, pp. 2-5, 1999.

[12] T. Tsukamoto and K. Takahashi, "Modeling of elevator control logic based on mark flow graph and its implementation on programmable logic controller," in Consumer Electronics (GCCE), 2014 IEEE 3rd Global Conference on. IEEE, 2014, pp. 599-600.

[13] A. Vidanapathirana, S. Dewasurendra, and S. Abeyratne, "Statechart based modeling and controller implementation of complex reactive systems," in Industrial and Information Systems (ICIIS), 2011 6th IEEE International Conference on. IEEE, 2011, pp. 493-498.

[14] A. A. E. Ali and Z. J. Min, "Design of five floors elevator with scada system based on s7200 plc, International Journal of Science and Research (IJSR), vol.5, no. 4, pp. 1309-1314, 2016."

[15] S. Zheng and F. Liu, "The design of elevator control system based on plc and configuration," in Advances in Computer Science, Intelligent System and Environment. Springer, 2011, pp. 743-748.

[16] M. Yağcı and M. E. Güven, "Anahtarlanalı relüktans motorların hız kontrolündeki titreşimlerin azaltılması," Selçuk-Teknik Dergisi, vol. 8, no. 3, pp. 161-175, 2009. 